\title{
A Closer Look: Assessment of Acute Pancreatitis Prognosis Using Neutrophil-Lymphocyte Ratio
}

\author{
Telma Fonseca ${ }^{1,2^{*}}$, João Miranda ${ }^{1}$, Vitor Devezas ${ }^{2}$, Marisa Aral ${ }^{2}$, Rui Mendes Costa ${ }^{1,2}$, J. Costa Maia ${ }^{2}$
}

* Corresponding author:

Telma Fonseca, MD

Alameda Professor Hernâni Monteiro

4200 Porto, Portugal

Telephone: 00351919409797

E-mail: tnvfonseca@gmail.com

Received: 21.12.2020

Accepted: 27.02.2021

$\overline{\text { Copyright } \odot \text { Celsius Publishing House }}$ www.sgo-iasgo.com
${ }^{1}$ Faculty of Medicine, University of Porto, Portugal

${ }^{2}$ Department of Surgery, S. Joao Medical Center, Porto, Portugal

\section{ABSTRACT}

Background/Objectives: Acute pancreatitis (AP) is a common cause of hospitalization and severe cases are usually associated with a poor prognosis. Neutrophil to lymphocyte ratio(NLR) has been pointed as an indicator of systemic inflammation in several disorders. The aim of this study was to assess whether NLR at admission is able to predict severity of AP and some associated outcomes, while trying to establish the best cut-off value for outcomes.

Materials and Methods: Single-center, retrospective study, reviewing clinical data from AP patients admitted between January 2014 and December 2015. Four hundred and forty five patients were eligible for the study and NLR was calculated based on admission laboratory data. Patients were stratified according to severity, based on the Atlanta Classification, and comparative analysis was carried between groups.

Results: A total of 391 patients presented with mild AP and 54 with moderate or severe AP. NLR for the severe group was significantly higher than for the mild group $(13.9 \pm 13.6$ versus 10.1 \pm 9.4 , respectively). There were also statistical differences in NLRs between all groups of analyzed outcomes except for in-hospital mortality. The best predictive NLR value for the stratification of AP severity was 9.2 .

Conclusions: This study shows a significant correlation between NLR at admission and the severity of AP. Higher NLR values also predicted the development of organ failure, ICU admission and longer hospitalizations.

Key words: acute pancreatitis, neutrophil, lymphocyte, prognosis, severity

\section{INTRODUCTION}

Acute pancreatitis (AP) is an inflammatory disorder of the pancreas caused by an impairment in the secretion of pancreatic enzymes, usually due to an obstruction of the pancreatic ducts (1). This leads to the accumulation of digestive enzymes in the acinar cells and interstitial space, which can be activated and cause acinar cell injury and a subsequent inflammation of the pancreatic parenchyma (2). The most common cause of AP is widely recognized to be gallstone disease (almost half of all cases) followed by alcohol consumption, while other causes (such as metabolic, toxic or iatrogenic) usually account for less than $10 \%$ of all episodes (3). In about one third of all patients, a cause is not found (4). 
AP still remains one of the most common causes of hospitalization due to gastrointestinal disease, with a reported worldwide increase in its incidence $(3,5)$. In fact, global epidemiological studies have found incidence rates for AP ranging from 13 to 45 cases per 100000 persons every year in occidental countries5. Mild cases of AP [MAP, approximately $80 \%$ of all episodes (1)] are usually characterized by edema and inflammation restricted to the pancreas, with no other complications. These are usually self-limited and carry very low morbidity and mortality rates $(6,7)$. On the other hand, patients presenting with moderate or severe AP (SAP) can develop multiple complications, such as organ failure and/or pancreatic necrosis, with mortality rates as high as $30 \%$ in the most complicated groups $(6,8)$.

Therefore, a prompt identification of the severe cases should occur in order to prevent worst outcomes, which seem to be related to an uncontrolled systemic inflammatory response with multiorgan failure $(8,9)$. For that reason, several scoring systems have been developed to help predict the severity of AP, including Ranson's criteria, Glasgow score, APACHE-II score, BISAP and imaging scores (like Balthazar's score and CTSI scores) $(2,10)$. However, these all have some major flaws that limit their use in the emergency department. For instance, both Ranson's and Glasgow criteria need a $48 \mathrm{~h}$ blood work-up (with some variables not routinely assessed) to be fully calculated, therefore missing the purpose of early identifying some severe cases; APACHE-II (Acute Physiology and Chronic Health Evaluation II) is a complex scoring system (not specific for acute pancreatitis) that requires more than 14 different variables; and BISAP (Bedside Index of Severity in Acute Pancreatitis), even though it is a simple score easily calculated in the emergency room, requires the realization of a chest $x$-ray. On the other hand, the imaging scoring systems (namely Balthazar's and CT Severity Index) demand performing an admission CT on all patients with suspected AP and did not exhibit better accuracy at predicting severe cases of AP (11). Furthermore, studies confirm that all described criteria have a relatively low sensitivity in the early phases of the disease $(10,12,13)$, probably because they equally weigh all the variables, not accounting for deleterious synergistic effects (13). For all the listed reasons, new forms of quickly, easily and accurately predict and evaluate the severity of new cases of AP are needed.

The neutrophil-lymphocyte ratio (NLR) is an easily obtained parameter from routine white blood cell counts, which are performed in almost all emergency admissions. For that reason, this parameter has been presented over the last decade as a predictor of poor outcomes in several gastrointestinal disorders (such as acute appendicitis, acute cholecystitis and some malignant neoplasms, like hepatocellular, esophageal and colorectal carcinomas), often being considered a more reliable tool than the total white blood cell count for that purpose (14-18). Regarding AP, some studies have shown a correlation between this ratio and the severity, mortality, length of hospitalization and need for ICU admission, demonstrating a prognostic value for the NLR with higher reliability than other common tools (19-21). On the other hand, there have been some conflicting results too, and there are some concerns regarding the real usefulness of this marker in this context (22-24). For instance, Gulen et al. proposed NLR was not effective at predicting AP mortality in the first 48 hours (22).

In this study, we aimed to assess whether NLR at admission correlates with AP severity and its adverse outcomes, namely need for ICU admission, longer length of stay (>7 days), presence of organ failure and in hospital mortality. We also studied the best NLR cut-off value to predict those outcomes.

\section{METHODS}

\section{Study design and patients}

We performed a retrospective cohort study including all patients with the diagnosis of AP admitted between $1^{\text {st }}$ January 2014 and $31^{\text {th }}$ December 2015 to Centro Hospitalar S. Joao, a tertiary care center in Oporto, Portugal. During this period, from 504 patients presenting with AP, 59 were excluded from data analysis for the following reasons: pediatric age $(n=10)$, HIV infection $(n=1)$, lymphoproliferative disorders $(n=4)$, immunosuppressive drugs $(n=5)$, iatrogenic etiology $(n=31)$ and missing clinical data $(n=8)$. A total of 445 patients were included.

\section{Data collection and definitions}

Data was obtained from electronic medical records and included demographic information (age, sex), laboratory data at admission, clinical data regarding the episode evolution (AP etiology, presence of pain, length of hospital stay, ICU admission, organ failure and in-hospital mortality) and radiologic findings (CT at admission or during hospitalization, if performed).

AP diagnosis was confirmed for each patient when at least two of the following criteria were present:

(1) abdominal pain suggestive of AP;

(2) serum amylase or lipase greater than three 
times the normal upper limit;

(3) typical radiological findings.

AP severity was defined based on the Revised Atlanta Classification (6), meaning patients were considered to have mild AP if there were no complications or presence of organ failure, moderately severe acute pancreatitis if there was transient organ failure (duration $<48 \mathrm{~h}$ ) and/or local or systemic complications, and severe acute pancreatitis if there was persistent organ failure (duration $\geq 48 \mathrm{~h}$ ). The modified Marshall scoring system (25) was used to determine the presence of organ failure, with a score of 2 or higher in each measurement indicating loss of organ function. For the purpose of statistical analysis, patients were divided into two groups: MAP (mild acute pancreatitis, with no complications or organ failure) and SAP (moderately severe and severe acute pancreatitis, with local or systemic complications and/or organ failure).

NLR was calculated by dividing the neutrophil count by the lymphocyte count for each patient at admission.

\section{Statistical analysis}

Statistical analysis was performed using IBM SPSS Statistics 25 , and a $p$ value $<0.05$ was accepted as statistically significant. Unless noted otherwise, categorical data was described using frequencies with proportions and continuous data using means with standard deviations. Comparison between groups was carried using the Fisher's exact or Chi-square tests for categorical data and Mann-Whitney $U$ or Student's t-test for continuous data, as appropriate. Correlation between NLR at admission and AP severity was determined based on Spearman's Rank coefficient. Receiver operating characteristic (ROC) curve analysis was performed for the studied outcomes with significant differences in NLR between groups in order to determine the best discriminating NLR cut-off value for each outcome. The optimal cut-off value for each ROC curve was computed based on the higher possible sensitivity and specificity values. Sensitivity, specificity, positive predictive value (PPV) and negative predictive value (NPV) were calculated for the results, and prediction accuracy was estimated using the area under the curve (AUC) for each ROC curve.

\section{RESULTS}

A total of 445 patients were included in the study, of which 391 presented with MAP (87.9\%) and 54 with SAP (12.1\%). The most common etiology for AP cases was biliary lithiasic ductal obstruction $(n=279,62.7 \%)$, followed by alcohol abuse ( $n=73,16.4 \%)$. In 72 cases (16.2\%), no cause for AP was found either during the episode or the follow-up. Patient demographics and laboratory data at admission are presented in table 1. Patients in the SAP group were significantly older, but no differences between groups were found regarding gender or etiology of pancreatitis. Need for ICU admission, prolonged hospital stay (> 7 days), organ failure and death were lower in the MAP group (table 1).

No differences were found in white blood cell counts (WBC) at presentation; on the other hand, the calculated mean NLR was significantly higher in MAP group (10.1 \pm 9.4 vs. $13.9 \pm 13.6$ for SAP, $p=0.003)$. The distribution of NLRs by severity of AP cases can be seen in fig. 1.

Regarding the occurrence of adverse outcomes, we found a statistically significant difference between NLR in patients admitted to the ICU (16.6 vs 9.7 in the other group; $\mathrm{p}<0.001$ ), in patients with a LOS $>7$ days ( 12.5 vs 9.3 in the group with LOS $<7$ days; $p<0.001$ ) and whenever organ failure was present (12.6 vs 10.1 if no organ failure occurred; $p=0.045)$. There were no statistically significant differences in NLR between groups according to in-hospital mortality (12.6 vs 10.4 , if death occurred or not, respectively; $p=0.099)$. A positive correlation between higher NLR values and severe cases was found using Spearman's correlation test $(r=0.130, p=0.003)$. A ROC curve for the prediction of AP severity using NLR was performed and the AUC for that curve was 0.623 (95\% Cl: 0.549-0.698); the NLR cut-off value determined for maximum accuracy was 9.2 (53.7\% sensitivity, $65.5 \%$ specificity, $17.8 \%$ positive predictive value and $91.1 \%$ negative predictive value). ROC analysis for NLR and secondary outcomes also

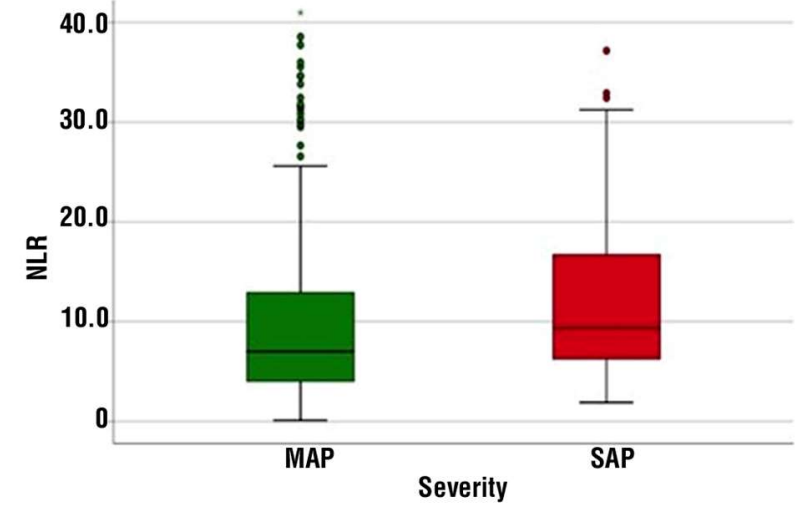

Figure 1 - NLR cases distribution by acute pancreatitis severity

Measures of position are as follows: MAP $-25^{\text {th }}$ percentile $=4.0$; Median $50^{\text {th }}$ percentile $=7.0 ; 75^{\text {th }}$ percentile $=12.9$. $S A P-25^{\text {th }}$ percentile $=6.1$; Median $/ 50^{\text {th }}$ percentile $=\mathbf{9} .3 ; 75^{\text {th }}$ percentile $=\mathbf{1 6 . 8}$. MAP $=$ mild acute pancreatitis; $\mathrm{SAP}=$ severe acute pancreatitis 
Table 1 - Sample descriptive statistics $(n=445)$

\begin{tabular}{|c|c|c|c|c|}
\hline & & All & MAP & SAP \\
\hline & $\mathbf{n}$ & 445 & 391 & 54 \\
\hline \multirow[t]{2}{*}{ Demographics } & Age (years) & $62.3 \pm 18.4$ & $61.1 \pm 18.1$ & $70.9 \pm 18.4$ \\
\hline & Gender. male (\%) & $250(56.2 \%)$ & $222(56.8 \%)$ & $28(51.9 \%)$ \\
\hline Etiology. n (\%) & $\begin{array}{l}\text { Biliary } \\
\text { Alcoholic } \\
\text { Idiopathic } \\
\text { Others }\end{array}$ & $\begin{array}{l}279(62.7 \%) \\
73(16.4 \%) \\
72(16.2 \%) \\
21(4.6 \%)\end{array}$ & $\begin{array}{l}245(62.7 \%) \\
66(16.9 \%) \\
60(15.3 \%) \\
20(5.1 \%)\end{array}$ & $\begin{array}{l}34(63.0 \%) \\
7(13.0 \%) \\
12(22.2 \%) \\
1(1.9 \%)\end{array}$ \\
\hline $\begin{array}{l}\text { Laboratory data } \\
\text { (at admission) }\end{array}$ & $\begin{array}{l}\text { Hemoglobin }(\mathrm{g} / \mathrm{dL}) \\
\text { White Blood Cells }\left(\times 10^{9} / \mathrm{L}\right) \\
\text { Neutrophils }\left(\times 10^{9} / \mathrm{L}\right) \\
\text { Lymphocytes }\left(\times 10^{9} / \mathrm{L}\right) \\
\text { Glucose }(\mathrm{mg} / \mathrm{dL}) \\
\text { C-Reactive Protein }(\mathrm{mg} / \mathrm{dL}) \\
\text { Total bilirrubin }(\mathrm{mg} / \mathrm{dL}) \\
\text { Direct bilirrubin }(\mathrm{mg} / \mathrm{dL}) \\
\text { Urea }(\mathrm{mg} / \mathrm{dL}) \\
\text { Creatinin }(\mathrm{mg} / \mathrm{dL}) \\
\text { LDH }(\mathrm{U} / \mathrm{L}) \\
\text { AST }(\mathrm{U} / \mathrm{L})\end{array}$ & $\begin{array}{l}13.7 \pm 1.9 \\
12.5 \pm 5.4 \\
10.2 \pm 5.6 \\
1.6 \pm 2.2 \\
142.7 \pm 60.7 \\
48.4 \pm 69.9 \\
2.0 \pm 2.1 \\
1.1 \pm 1.6 \\
41.7 \pm 26.0 \\
1.0 \pm 0.83 \\
381.2 \pm 427.6 \\
250.7 \pm 497.4\end{array}$ & $\begin{array}{l}13.9 \pm 1.8 \\
12.5 \pm 5.3 \\
10.1 \pm 5.6 \\
1.7 \pm 2.3 \\
140.0 \pm 54.1 \\
42.7 \pm 65.8 \\
2.0 \pm 2.1 \\
1.0 \pm 1.6 \\
37.3 \pm 16.4 \\
0.8 \pm 0.3 \\
374.0 \pm 391.2 \\
249.6 \pm 433.0\end{array}$ & $\begin{array}{l}12.2 \pm 2.4 \\
12.8 \pm 6.2 \\
10.6 \pm 5.6 \\
1.1 \pm 0.9 \\
163.3 \pm 95.8 \\
88.6 \pm 84.1 \\
2.2 \pm 2.4 \\
1.2 \pm 1.6 \\
74.1 \pm 50.1 \\
2.2 \pm 1.9 \\
423.4 \pm 603.8 \\
258.5 \pm 823.8\end{array}$ \\
\hline Clinical data & $\begin{array}{l}\text { Abdominal pain. } n(\%) \\
\text { Death. } n(\%) \\
\text { ICU admission. } n(\%) \\
\text { LOS (days) } \\
\text { LOS > } 7 \text { days. } n(\%) \\
\text { Organ Failure. } n(\%) \\
\text { NLR }\end{array}$ & $\begin{array}{l}428(96.2 \%) \\
18(4.0 \%) \\
51(11.5 \%) \\
9.0 \pm 12.9 \\
171(38.5 \%) \\
46(10.3 \%) \\
10.1 \pm 9.4 \\
\end{array}$ & $\begin{array}{l}377(96.4 \%) \\
6(1.5 \%) \\
29(7.4 \%) \\
8.0 \pm 11.1 \\
139(35.6 \%) \\
0(0 \%) \\
10.1 \pm 9.4\end{array}$ & $\begin{array}{l}51(94.4 \%) \\
12(22.2 \%) \\
22(40.7 \%) \\
15.8 \pm 20.6 \\
32(59.3 \%) \\
46(85.1 \%) \\
13.9 \pm 13.6 \\
\end{array}$ \\
\hline
\end{tabular}

Data is presented as mean \pm standard deviation. unless noted otherwise.

$\mathrm{MAP}=$ mild acute pancreatitis. SAP = severe acute pancreatitis. $\mathrm{LDH}=$ Lactate dehydrogenase. $\mathrm{AST}=$ Aspartate transaminase

ICU = intensive care unit. LOS = length of stay. NLR = neutrophil-lymphocyte ratio.

selected 9.2 as the most accurate cut-off value at predicting organ failure and need for ICU admission; meanwhile, LOS>7 days was better predicted with a cut-off point of 7.9. AUC for all ROC curves and respective optimal cut-off points are presented in table 2. Sensitivity, specificity and predictive values for the chosen cut-off (NLR $=9.2)$ at predicting the evaluated outcomes are presented in table 3.

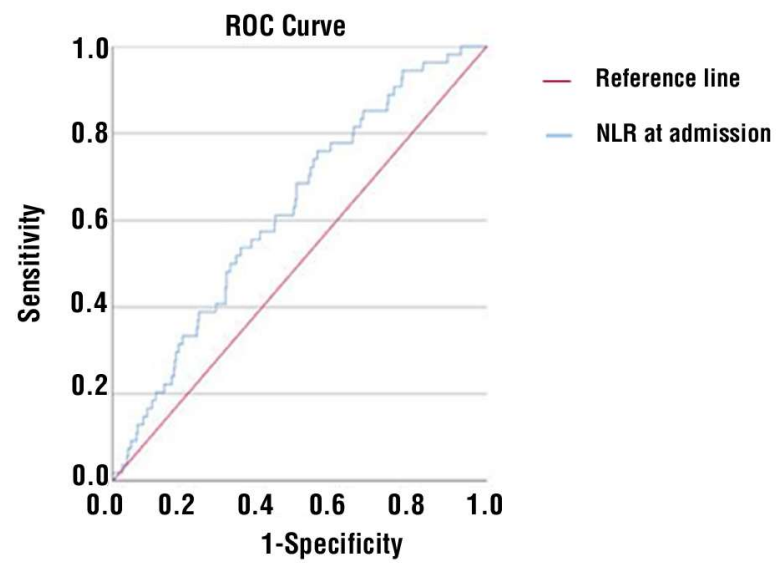

Figure 2 - ROC curve for NLR at admission predicting AP severity

\section{DISCUSSION}

Multiple studies have previously shown the usefulness of NLR at predicting disease severity, recurrence and prognosis in several disorders (14-18). In particular, NLR has been studied as a predictor of AP severity and unfavorable prognosis, often being proposed as an effective tool for that purpose (19-21). Neutrophils have been shown to play a pivotal role in the propagation of the inflammation pathways in AP through cytokine and chemokine cascades, trypsin production (26). Regarding lymphocyte counts, lymphocyte depletion was demonstrated in severe cases of AP, mainly because of premature apoptotic death of these cells (especially T CD8 subpopulations) (27). For these reasons, it is expected that AP cases associated with

Table 2 - AUC of ROC curves for each studied outcome and their respective cut-off value with better performance (higher sensitivity and specificity)

\begin{tabular}{llc}
\hline Outcome & AUC $\mathbf{( 9 5 \%} \mathbf{~ C l})$ & Optimal NLR cut-off \\
\hline Severity & $0,623(0,549-0,698)$ & 9,21 \\
\hdashline Organ failure & $0,614(0,530-0,698)$ & 9,20 \\
\hline LOS $>7$ days & $0,605(0,551-0,659)$ & 7,89 \\
\hline ICU admission & $0,684(0,600-0,768)$ & 9,17 \\
\hline
\end{tabular}


Table 3 - Sensitivity, specificity, PPV and NPV of cut-off point NLR = 9,2 at predicting AP severity, occurrence of organ failure, need for ICU admission and length of stay $>7$ days.

\begin{tabular}{|c|c|c|c|c|}
\hline & Sensitivity & Specificity & PPV & NPV \\
\hline Severity & $53.7 \%$ & $65.5 \%$ & $17.8 \%$ & $91.1 \%$ \\
\hline Organ Failure & $54.3 \%$ & $65.3 \%$ & $15.2 \%$ & $92.5 \%$ \\
\hline ICU admission & $68.6 \%$ & $57.0 \%$ & $20.7 \%$ & $94.5 \%$ \\
\hline LOS $>7$ days & $47.6 \%$ & $69.2 \%$ & $50.6 \%$ & $66.7 \%$ \\
\hline
\end{tabular}

necrosis or organ failure (i.e., SAP cases) develop higher levels of neutrophilia and lymphopenia, translating into higher NLR values (28). As mentioned before, the most practical advantage of this parameter is the fact that it is readily obtained from a routine blood count with leucocyte count in the emergency department, not needing further workups.

In this study, we focused on assessing whether higher values of NLR calculated at admission correlated with worse outcomes. Our results show that SAP cases were generally associated with higher values of NLR than those of the MAP cases, therefore being an useful tool for stratification of AP severity. We also found NLR to be significantly higher in patients admitted to the ICU, with longer lengths of stay and with presence of organ failure [one of the most important factors in defining AP severity, as indicated by the Atlanta Classification of Acute Pancreatitis (6)].

The biggest differences between studies regarding NLR in AP concern the optimal cut-off value for the severity stratification. Azab et al. (19) and Jeon and Park (20) suggested that the optimal NLR cut-off value at admission should be 5 or 4.76 , respectively, while Suppiah et al. (21) proposed it to be 10.6. We found higher sensitivity and specificity in predicting SAP cases with a cut-off point of $9.2(62.3 \%$ accuracy, as determined by the AUC of the ROC curve), which is way closer to what Suppiah et al. found. We also could confirm the superiority of NLR over WBC count in distinguishing between MAP and SAP cases, as proposed by Azab et al., considering we found no statistically significant differences in WBC between both groups.

Our study also showed that the NLR also demonstrates a decent accuracy at predicting the need for ICU admission (AUC 0.684), presence of organ failure (AUC 0.614 ) and length of stay $>7$ days (AUC 0.605), but not at predicting in-hospital mortality (unlike previous studies), possibly because of the insufficient sample size. From the presented data, we may conclude that NLR at admission performs better at predicting need for ICU admission comparing to the other examined outcomes, but its low positive predictive value possibly presents itself as an obstacle for that purpose, considering the high rate of false positives.

Even though the accuracy of NLR in predicting AP severity may be lower than the reported accuracy of other currently used scoring systems (29), the present study (and any other else, to our knowledge) directly compared these, and for that reason further research on the subject should be conducted. On the other hand, instead of considering NLR as an independent tool to predict AP severity, maybe it should associated to other laboratory markers (and/or possibly already existing scoring systems) in order to improve its accuracy and diagnostic performance. Prospective research should be conducted for that matter.

Our study presents some obvious limitations, mainly concerting the investigation design. As a retrospective study, a selection bias, inherent to this type of studies, is often present; the outcomes assessment heavily depended on the medical records provided by others. A bigger sample size would also benefit the study, especially considering one of the outcomes (in-hospital mortality) that could not be correctly evaluated because of lack of cases.

\section{CONCLUSION}

In conclusion, this study shows evidence that the NLR at admission of patients presenting with AP should be considered as an effective, easy and rapid tool of assessing AP severity and adverse outcomes (namely, development of organ failure, need for ICU admission and longer hospitalizations). A cut-off point of 9,2 appears to be the most accurate at predicting all the above mentioned outcomes in this sample.

\section{Conflicts of Interest and Source of Funding}

None of the authors has conflicts of interest or financial ties to disclose. No funding was required for this paper. 


\section{Ethical approval}

The study was approved by the Ethical Committee "Comissão de Ética para a Saúde do Centro Hospitalar S. Joao". The confidentiality and privacy of the data were guaranteed according to the Declaration of Helsinki.

\section{REFERENCES}

1. Forsmark CE, Vege SS, Wilcox CM. Acute Pancreatitis. N Engl J Med. 2016;375(20):1972-1981.

2. Lankisch PG, Apte M, Banks PA. Acute pancreatitis. The Lancet, 2015;386(9988):85-96

3. Yadav D LA. Trends in epidemiology of the first attack of acute pancreatitis. Pancreas. 2006;33(4):8.

4. Yijun Chen YZ, Hernandez-Boussard T, Park W, Visser BC. The Epidemiology of Idiopathic Acute Pancreatitis, Analysis of the Nationwide Inpatient Sample From 1998 to 2007. Pancreas. 2015; 42(1):5.

5. Yadav D, Lowenfels AB. The epidemiology of pancreatitis and pancreatic cancer. Gastroenterology. 2013;144(6):1252-61.

6. Banks PA, Bollen TL, Dervenis C, Gooszen HG, Johnson CD, Sarr MG, et al. Classification of acute pancreatitis--2012: revision of the Atlanta classification and definitions by international consensus. Gut. 2013;62(1):102-11.

7. Singh VK, Bollen TL, Wu BU, Repas K, Maurer R, Yu S, et al. An assessment of the severity of interstitial pancreatitis. Clin Gastroenterol Hepatol. 2011:9(12):1098-103

8. Mofidi R, Duff MD, Wigmore SJ, Madhavan KK, Garden OJ, Parks RW. Association between early systemic inflammatory response severity of multiorgan dysfunction and death in acute pancreatitis. $\mathrm{Br}$ J Surg. 2006:93(6):738-44.

9. Petrov MS, Shanbhag S, Chakraborty M, Phillips AR J, Windsor JA Organ failure and infection of pancreatic necrosis as determinants of mortality in patients with acute pancreatitis. Gastroenterology. 2010; 139(3):813-20.

10. Kuo DC, Rider AC, Estrada P, Kim D, Pillow MT. Acute Pancreatitis: What's the Score?J Emerg Med. 2015;48(6):762-70.

11. Bollen TL, Singh VK, Maurer R, Repas K, van Es HW, Banks PA, et al. A comparative evaluation of radiologic and clinical scoring systems in the early prediction of severity in acute pancreatitis. Am J Gastroenterol. 2012;107(4):612-9.

12. Harshit Kumar A, Singh Griwan M. A comparison of APACHE II, BISAP, Ranson's score and modified CTSI in predicting the severity of acute pancreatitis based on the 2012 revised Atlanta Classification. Gastroenterol Rep (Oxf). 2018;6(2):127-131.

13. Papachristou GI, Muddana V, Yadav D, O'Connell M, Sanders MK Slivka A, et al. Comparison of BISAP, Ranson's, APACHE-II, and CTSI scores in predicting organ failure, complications, and mortality in acute pancreatitis. Am J Gastroenterol. 2010;105(2): 435-41; quiz 442.
14. Hao Duan XZ, Wang FX, Cai MY, Ma GW, Yang H, Fu JH, et al. Prognostic role of neutrophil-lymphocyte ratio in operable esophageal squamous cell carcinoma. World J Gastroenterol. 2015; 21(18):5591-7.

15. Kahramanca S, Ozgehan G, Seker D, Gökce El, Seker G, Tunç G, et al., Neutrophil-to-lymphocyte ratio as a predictor of acute appendicitis. Ulus Travma Acil Cerrahi Derg. 2014;20(1):19-22.

16. Kayadibi H, Sertoglu E, Uyanik M, Tapan S. Neutrophil-lymphocyte ratio is useful for the prognosis of patients with hepatocellular carcinoma. World J Gastroenterol. 2014;20(28):9631-2.

17. Li MX, Liu XM, Zhang XF, Zhang JF, Wang WL, Zhu Y, et al. Prognostic role of neutrophil-to-lymphocyte ratio in colorectal cancer: a systematic review and meta-analysis. Int J Cancer. 2014; 134(10):2403-13.

18. Sato N, Kinoshita A, Imai N, Akasu T, Yokota T, Iwaku A, et al. Inflammation-based prognostic scores predict disease severity in patients with acute cholecystitis. Eur J Gastroenterol Hepatol. 2018; 30(4):484-489

19. Azab B, Jaglall N, Atallah JP, Lamet A, Raja-Surya V, Farah B, et al. Neutrophil-lymphocyte ratio as a predictor of adverse outcomes of acute pancreatitis. Pancreatology. 2011;11(4):445-52.

20. Jeon TJ, Park JY. Clinical significance of the neutrophil-lymphocyte ratio as an early predictive marker for adverse outcomes in patients with acute pancreatitis. World J Gastroenterol, 2017. 23(21):38833889.

21. Suppiah A, Malde D, Arab T, Hamed M, Allgar V, Smith AM, et al. The prognostic value of the neutrophil-lymphocyte ratio (NLR) in acute pancreatitis: identification of an optimal NLR. J Gastrointest Surg. 2013;17(4):675-81.

22. Gulen B, Sonmez E, Yaylaci S, Serinken M, Eken C, Dur A, et al. Effect of harmless acute pancreatitis score, red cell distribution width and neutrophi//ymphocyte ratio on the mortality of patients with nontraumatic acute pancreatitis at the emergency department. World J Emerg Med. 2015;6(1):29-33.

23. Binnetoglu $E$, Akbal $E$, Günes $F$, Sen $H$. The prognostic value of neutrophil-lymphocyte ratio in acute pancreatitis is controversial. J Gastrointest Surg. 2014;18(4):885

24. Li Y, Zhao Y, Feng L, Guo R. Comparison of the prognostic values of inflammation markers in patients with acute pancreatitis: a retrospective cohort study. BMJ Open. 2017;7(3):e013206.

25. Marshall JC, Cook DJ, Christou NV, Bernard GR, Sprung CL, Sibbald WJ. Multiple organ dysfunction score: a reliable descriptor of a complex clinical outcome. Crit Care Med. 1995;23(10):1638-52.

26. Yang ZW, Meng XX, Xu P. Central role of neutrophil in the pathogenesis of severe acute pancreatitis. J Cell Mol Med, 2015. 19(11):2513-20.

27. Takeyama Y, Takas K, Ueda T, Hori Y, Goshima M, Kuroda Y. Peripheral lymphocyte reduction in severe acute pancreatitis is caused by apoptotic cell death. J Gastrointest Surg. 2000; 4(4):379-87.

28. Zahorec R. Ratio of neutrophil to lymphocyte counts--rapid and simple parameter of systemic inflammation and stress in critically ill. Bratisl Lek Listy. 2001;102(1):5-14. English, Slovak

29. Cho JH, Kim TN, Chung HH, Kim KH. Comparison of scoring systems in predicting the severity of acute pancreatitis. World $\mathrm{J}$ Gastroenterol. 2015;21(8):2387-94. 